\title{
Information Technology Issues Faced By The Business World
}

Ihssan Alkadi, (Email: ixa6880@louisiana.edu), University of Louisiana, Lafayette

Zhiwei Zhu, University of Louisiana, Lafayette

\begin{abstract}
As the "information age" becomes more centered around technology, the disparity between the use and spread of information technology between developed and developing countries becomes more obvious. This digital divide further alienates developing nations from the global economy. However, rapid changes and advances in technology cannot be ignored. Those developed and technologically advanced nations, such as the United States, use technology to the best of their advantage, especially in the business world. Because of this, many businesses are turning to the practice of outsourcing. With so many people using technology, many potential problems exist. An increasing number of people using technology calls for a need of security. Many individuals and businesses are obtaining this security through the use of firewalls. Information technology and the need to protect information are important issues in the business world today.
\end{abstract}

\section{DIGITAL DIVIDE}

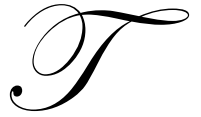

echnology is playing an increasingly important role in today's business world. The digital divide between developed and underdeveloped countries is even more imminent. There is a digital divide between developed and developing countries not only in "their use of computers to prepare students for the global economy,' but also in the way these countries do business (Kozma, 2004). The socioeconomic factors in different countries have an effect on that country's technology (Azari, 2004). The digital divide becomes even more obvious when technology in places such as the United States becomes even more advanced. It is important for people in our society to have the ability to use technology for many reasons. Computers are now essential tools for learning. For example, if a person wanted to expand his/her education, he/she would have to know how to use a personal computer as a tool for completing assignments, conducting research, and also as a communication tool. Most instructors use e-mail as their main source of communication with students. Those students that have trouble using computers have trouble staying current with class events. Also, computers not only serve as a tool to assist teachers, but also can be the "teacher". This statement applies to the modern education institution where more and more classes are being offered online and also to the workplace where many employees are trained by computers and it is essential that they know how to use them to perform their jobs effectively and efficiently. Computers and other technological tools are now being used more than ever in public places. For example, many major stores, like Wal-Mart and Target, now use an electronic gift registry. If someone wanted to buy a gift for a friend who is getting married, he/she would have to be able to use the electronic registry to obtain a listing of requested gifts.

It is also important to have the ability to use a computer because of the competition in acquiring a job. An employer will most likely ask applicants about their computer skills and will almost certainly hire a person with technological skills than one without these skills. Also, many job listing can only be obtained from the Internet. Those who do not know how to use a computer will never have the opportunity to seek those jobs.

\section{DISTRIBUTION OF TECHNOLOGY}

It is obvious that the ability to use technology is becoming an essential proficiency in our society. The Digital Divide is causing the technologically advanced to move forward at an amazing rate as the technologically challenged 
stay behind and watch the world move on. What is interesting about this divide is the distribution of the technologically advanced among different income groups, which will be discussed shortly.

In 1998 it was estimated that $36.6 \%$ of the United States population had a computer in the home and in 2001, $51.5 \%$ of the population had a computer in the home. This shows that the amount of people using computers is growing very rapidly and parts of our society are becoming more technologically adept-see Figure 1. Another interesting thing about the Digital Divide is the rate at which certain income groups are acquiring technological abilities, which also will be discussed shortly.

Figure 1

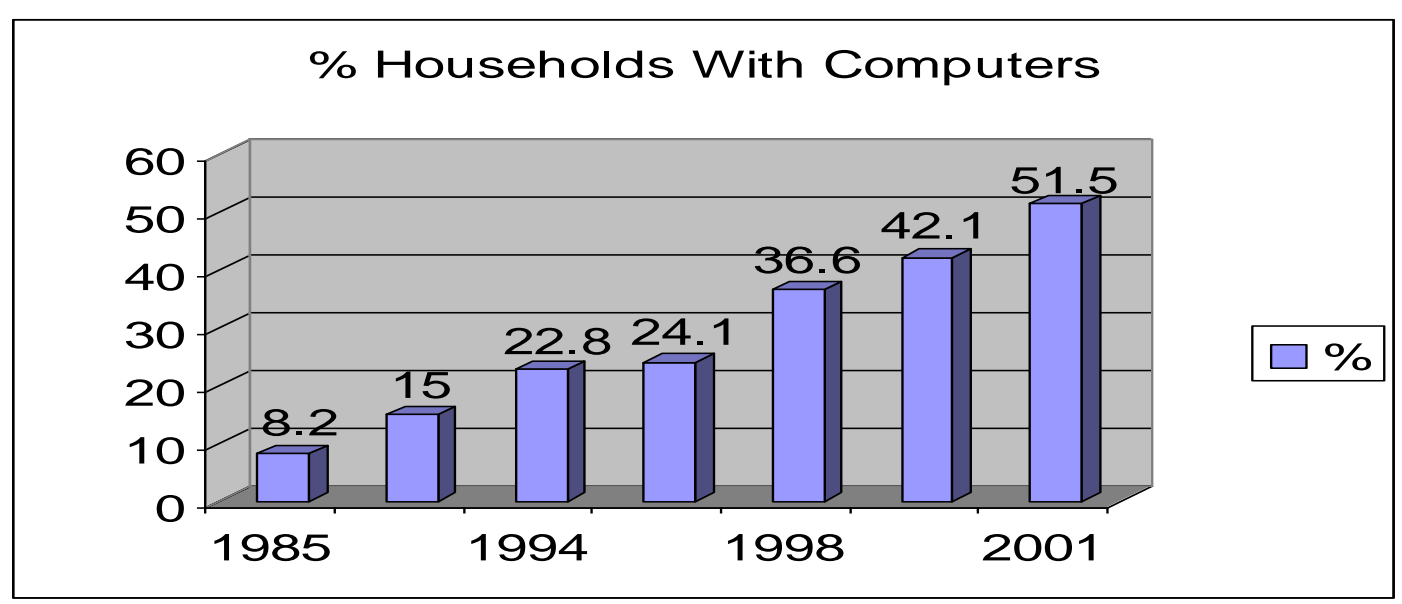

The above chart shows the percentage of people in the U.S. with computers in the household. However not everyone who knows how to use a computer has one at home. In 2001 it was estimated that $53.5 \%$ of the U.S. population knew how to use a computer, and $51.5 \%$ of the population had a computer in the household. This means that only $2 \%$ of those who did not own a computer knew how to use one which means either that people are not buying computers because they do not know how to use them, or they do not know how to use computers because they cannot afford them.

The potential causes of a lack of computer skills also may apply differently to different socio-economic groups. We believe that many people in lower incomes levels do not know how to use a computer because they cannot afford to purchase one. This fact is shown by the distribution of people who own computers and use them when categorized by income - see Figure 2. The proportion of people in the United States who have access to computers when categorized by income increases with annual salary. In 2001, of the people who made from $\$ 0$ to $\$ 15,000$ per year, about 37\% knew how to use a computer and about $19 \%$ owned a computer. In contrast, of the people who made more than $\$ 75,000$ per year, about $89 \%$ knew how to use a computer and about $87 \%$ owned a computer. This shows that people with higher incomes are much more likely to use and own a computer than those with lower incomes.

We also believe that there may be a certain amount of "resistance" to computer use within other socioeconomic groups. For example, some elderly individuals may not be willing to purchase a computer, even though they can afford to do so, because they lived most of their lives in an era when computer proficiency was required to function effectively in society or the workplace. However, other elderly individuals may find that acquiring a computer and computer skills may help them "stay in touch" with others in their lives or even make new friends. This is an issue that needs further investigation. 
Figure 2

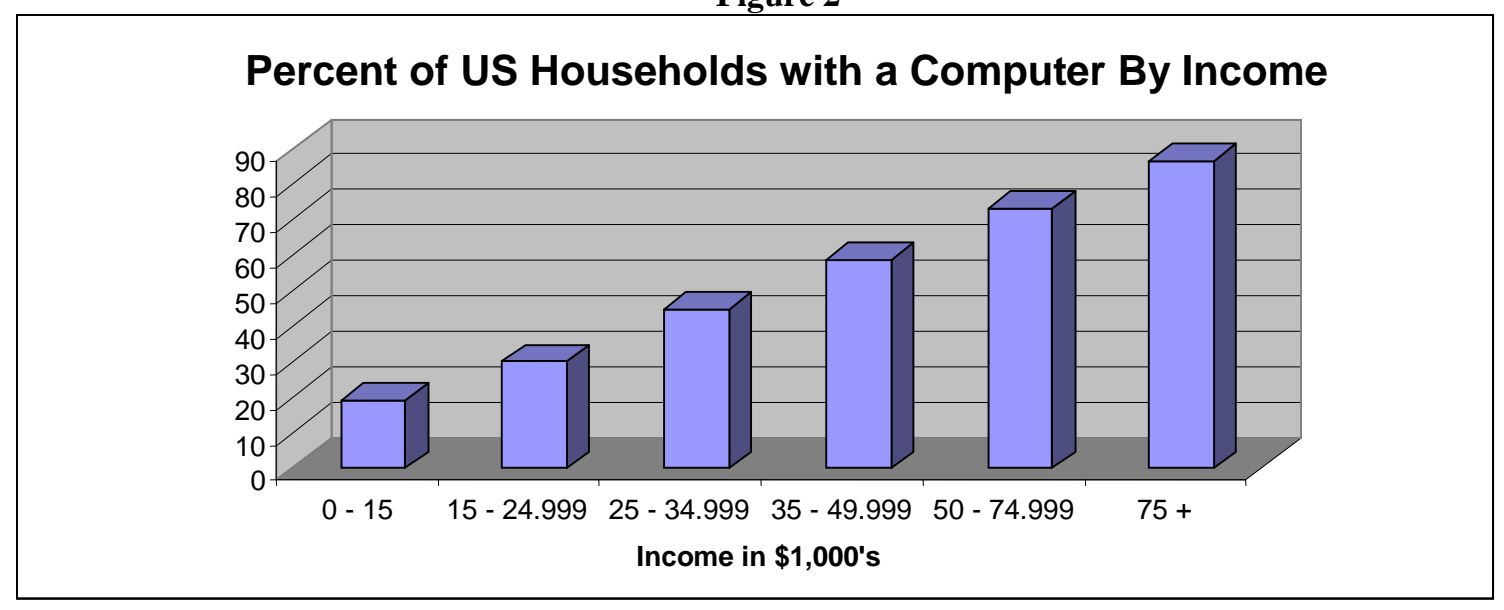

Another technological ability that has been growing at an enormous rate, especially in the past 10 years, is the use of the Internet. The proportions of people (1) who have access to the Internet and (2) who have access to the Internet in the household closely parallels the proportions of those (1) who have access to computers and (2) those who have computers in the household. The differences in Internet usage are very apparent when stratifying Internet users by income - see Figure 3. Similar to computer use, those with higher incomes use the Internet more than those with lower incomes. In 2000 , only $18.9 \%$ of individuals who made less than $\$ 15,000$ per year used the Internet. In contrast, $70.1 \%$ of people who made more than $\$ 75,000$ per year used the Internet.

Figure 3

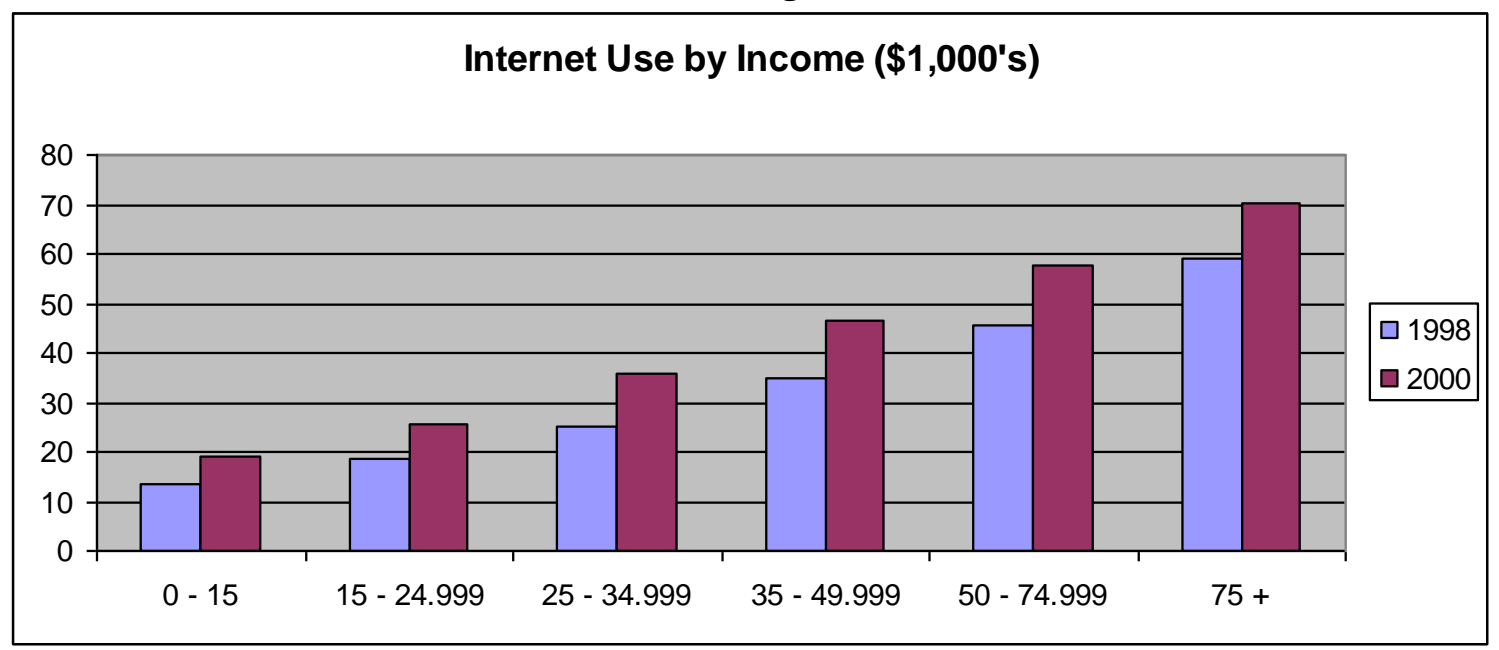

\section{EFFECTS OF THE DIGITAL DIVIDE}

The Digital Divide is simply a division between people who have access to certain information and communication technologies and those who do not. It is the natural result of living in a free market society that only some people to have access to certain information and communication technologies and the knowledge to use it. Consequently, the question that must be asked is "Is the digital divide a problem?". 
We believe that the Digital Divide is a problem. People who have access to certain information and communication technologies and the knowledge to use those technologies have an enormous advantage over those who do not. In our current economy, information and knowledge are the tools with which to advance on the socioeconomic "ladder." Consequently, individuals without access to certain information and communication technologies may be unable to improve their working and living conditions while those with access to those resources have the ability to significantly improve their situations. The result is that the digital divide exacerbates the socio-economic division within our society - the "haves" become wealthier and more successful while the "have nots" continue to suffer from a lack of material goods and "upward mobility."

Some disadvantages of not having access to modern information and communication technologies in the household are obvious. In general, e-mail users are more informed than non-users. Whether they get news information through e-mail, communicate with teachers, or communicate with family members, e-mail users are generally more informed about the world, our nation, our communities, and our economy than those without e-mail. In the workplace, employees that use e-mail for work purposes are more informed about important workplace issues than those who do not. This is an advantage for the employees and also for the organization. Students who have access to the Internet and know how to use it have great advantages over those who do not. Even those students who do not know how to use the Internet, but know how to use a computer still have an enormous advantage over those who do not know how to use a computer.

Most importantly, because people with Internet and computer knowledge and access have such advantages as mentioned above, they tend to stay more up-to-date with current information and communication technologies than those who do not. Because of this, the technologically-advanced continue to move ahead within society while the technologically bereft are left behind.

\section{THE DIGITAL DIVIDE (THE HAVE AND HAVE-NOTS)}

The Digital Divide is the fact that people, cultures, and areas of the world, or within a nation do not have the same access to information technology. Being from one of the most powerful nations in the world, as Americans we take for granted the fact that just about everybody we know has access to a computer. But what causes the digital divide? It is a product of poverty, bad politics, and social injustices. No matter which perspective you see it through; it turns into a clear-cut case of the "have and have-nots." We have to understand that this problem does exist, even in our country, and fix it. Naturally, the social and economic factors of a country have an effect on the country's technology. "Technology does not develop by itself but in concert with pre-disposing characteristics of the environment" (Azari, 2004). While information technology (IT) is advancing in some areas, there is a disparity in the use and spread of IT between developed and developing nations. Those with IT have easier access to information and communication. They have easier access to the global economy (Weerasinghe, 2004). Those with little or no IT are further alienated from the global economy by this digital divide.

\section{CAUSES OF THE DIGITAL DIVIDE}

People who do not have access to technologies such as computers and the Internet do not lack access because they never learned to use these technologies. With computers becoming more easily accessible outside the home, income levels are becoming less relevant when looking at who has access to computers and the Internet. However, if people are not taught to use those public computers, the divide will remain.

Even though income is becoming a smaller factor in determining who has access to computers and the Internet, it still is an important factor. Those who are able to afford computers in the household are much more likely to learn how to use them. As mentioned earlier, in 2000, there was a drastic difference in the proportion of the United States population who had computers in the household when stratified by income.

Another factor preventing some people from learning how to use new technologies is the design of those technologies. Although computers are becoming easier for beginners to use, many other related technologies are not designed for beginners. Many of today's technologies are designed for people who already possess the skills to use 
them. For example, wireless networking technologies provide individuals with the ability to easily link computers throughout their home and/or workplace. However, setting up a wireless LAN can be an exercise in frustration if the user is not familiar with the networking portion of their computer operating system(s) and data communication issues such as IP conflicts.

\section{CLOSE THE DIVIDE}

One factor that can help to close the Digital Divide is education. Unfortunately, many people in our society will not get a "standard" education and, thus, will not learn the IT skills necessary to succeed in today's information economy. Although it is not possible to ensure that everyone will get an education, it is possible to ensure that those who do get a public education will be taught the necessary technology skills to be a part of the "haves" group. An increasing amount of public schools are requiring some type of technology in the classroom to teach students how to use computers and the Internet.

More libraries are now proving Internet access on public computers that can be used by everyone. This means that in the near future, Internet and computer access will be available for nearly everyone. However, many older people and socio-economically disadvantaged individuals do not have the skills to use these technologies and have no way of learning them. A solution to this issue is to offer free or low cost public classes to these individuals to teach them the skills necessary to use and benefit from modern information and communication technologies.

The cost of technology, although becoming less relevant of an inhibiting factor because of the increasing level of public offerings of computer and Internet access, is still a factor in determining who will have the ability to use today's technology. As technology prices continue to fall, more people will be given the opportunity to acquire computers and other related technologies. As costs continue to drop, more people will be willing to accept and learn to use these technologies.

Perhaps the Federal, State and local governments can help to lessen the digital divide by providing more publicly available computers with Internet access, conducting campaigns to inform socio-economically challenged individuals of the benefits that can accrue to them once they learn to use these resources effectively, and providing free technology seminars give these individuals the skills necessary to use these technologies effectively. Not only would these programs help to alleviate some of the other costs associated with assisting socio-economically disadvantaged groups, but they also would increase the supply of IT literate workers available to employers. These programs could be provided (1) through universities for those individuals who have a certain minimum level of education and (2) through other community outreach facilities for those individuals lacking the minimum educational requirements for programs in the first group.

\section{CONCLUSION}

The partitioning of our society into the "haves" and "have-nots" of technology, known as the Digital Divide, is certainly a problem in our society. The "have-nots" of technology are falling further behind while the "haves" are surging forward into the future. Those who have the knowledge to use today's technology have many great advantages, including advanced communication abilities, learning opportunities, and better job opportunities. These advantages are causing the technologically deprived to fall increasingly further behind. If our society can help them to learn these skills, we can ensure that nobody will be left behind in the technological wave.

\section{WORKS CITED}

1. Azari, Rasool and James Pick. Technology and Society: Socioeconomic Influences on Technological Sectors for United States Countries. International Journal of Information Management. Volume 25. Issue 1. February, 2005.

2. Bahli, Bouchaib and Suzanne Rivard. Validating Measures of Information Technology Outsourcing Risk Factors. Omega. Volume 33. Issue 2. April 2005. 
3. Choy, K.L., Choy, L.C., Lau, Henry, and W.B. Lee. A Knowledge-Based Supplier Intelligence Retrieved System for Manufacturing. Knowledge-Based Systems. Volume 18. Issue 1. February, 2005.

4. Doddrell, Gregory R. Information Security and the Internet. Internet Research Bradford. Volume 6. Issue 1. 1996.

5. Keromytis, Angelos and Prevelakis, Vassilis. Drop-in Security for Distributed and Portable Computing Elements. Internet Research. Volume 13. Issue 2. 2003.

6. Kozma, Robert, McGhee, Ray, Quellmalz, Edys, and Dan Zalles. Closing the Digital Divide: Evaluation Of the World Links Program. International Journal of Educational Development. Volume 24 Issue 4. July 2004.

7. Lambert, Joyce C. and Carolyn L. Losteau. New Aspects of Test Security. TH E Journal. Volume 29. Issue 1. August 2001.

8. Ross, J. W. and G. Westerman. Preparing for Utility Computing: The Role of IT Architecture and Relationship Management. Retrived from sciencedirect.com March 2005.

9. Weerasinghe, Samantha. Revolution Within the Revolution: the Sri Lankan Attempt to Bridge the Digital Divide Through E-Governance. The International Information and Library Review. Volume 36. Issue 4. December 2004.

10. Wein, Elmar. Outsourcing Measures to Improve Plausibility. Statistical Journal of the United Nations. IOS Press. March 2005.

\section{NOTES}

